This item was submitted to Loughborough's Research Repository by the author.

Items in Figshare are protected by copyright, with all rights reserved, unless otherwise indicated.

\title{
The adoption of STEP-NC for the manufacture of asymmetric rotational
} components

PLEASE CITE THE PUBLISHED VERSION

PUBLISHER

Professional Engineering Publishing / @ IMechE

VERSION

VoR (Version of Record)

LICENCE

CC BY-NC-ND 4.0

\section{REPOSITORY RECORD}

Rosso, Roberto S.U., Stephen T. Newman, and Shahin Rahimifard. 2019. "The Adoption of STEP-NC for the Manufacture of Asymmetric Rotational Components”. figshare. https://hdl.handle.net/2134/5064. 
This item was submitted to Loughborough's Institutional Repository (https://dspace.lboro.ac.uk/) by the author and is made available under the following Creative Commons Licence conditions.

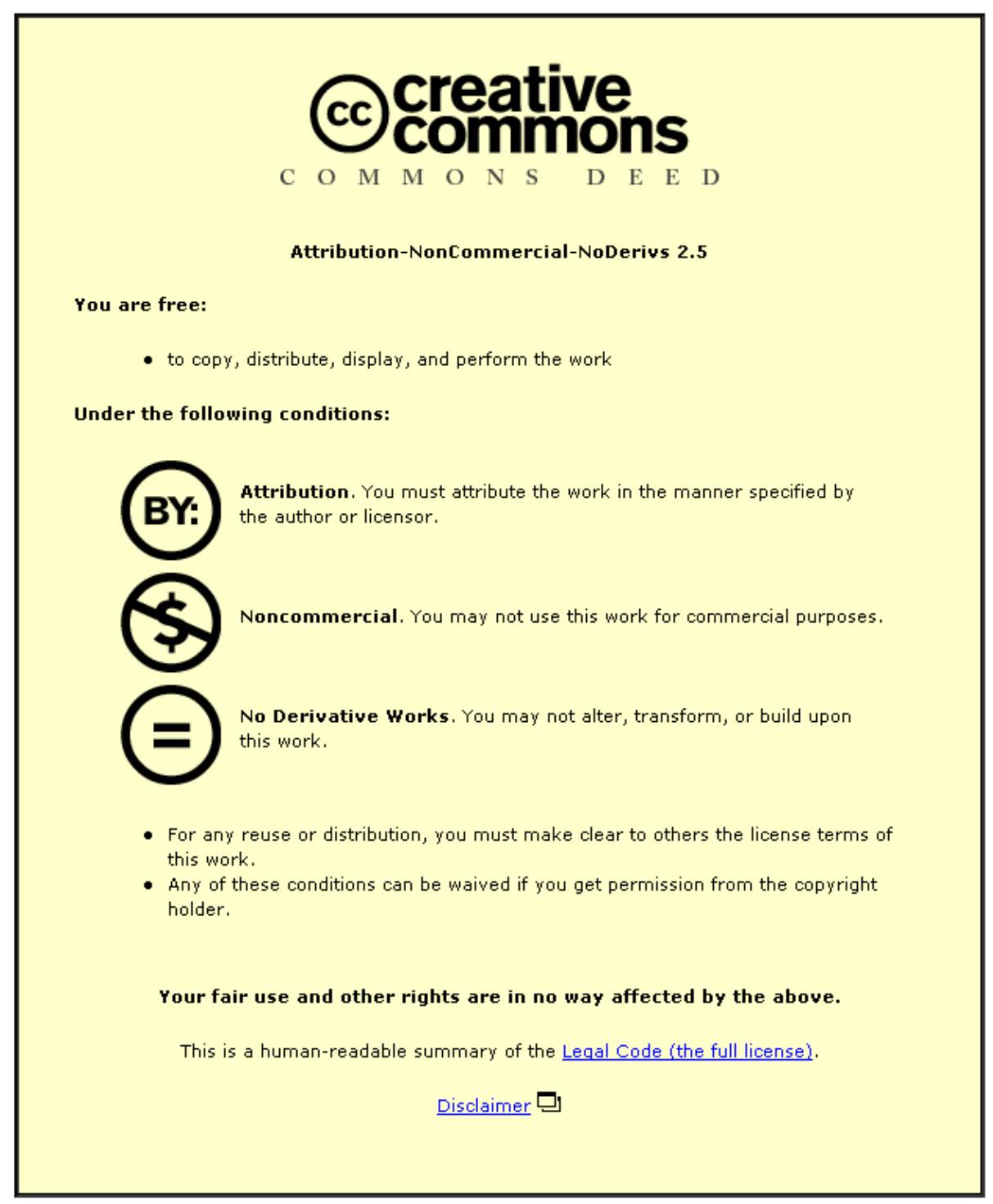

For the full text of this licence, please go to: http://creativecommons.org/licenses/by-nc-nd/2.5/ 


\title{
The adoption of STEP-NC for the manufacture of asymmetric rotational components
}

\author{
R S U Rosso Jr ${ }^{1}$, S T Newman ${ }^{2 *}$ and S Rahimifard ${ }^{2}$ \\ ${ }^{1}$ Department of C. Science, Universidade do Estado de Santa Catarina, Joinville, Brazil \\ ${ }^{2}$ Wolfson School of Mechanical and Manufacturing Engineering, Loughborough University, Loughborough, UK
}

\begin{abstract}
This paper reports ongoing research on the use of the evolving ISO 14649 standard, informally termed STEP-NC, which represents a new data model for the next generation of computer numerical controllers. The paper presents the major challenges in implementing STEPcompliant $\mathrm{CAD} / \mathrm{CAM}$ (computer-aided design/manufacture) systems for manufacturing asymmetric rotational parts. It also discusses the need for a new ISO 14649 schema specific for asymmetric rotational parts and outlines a feasible solution to use the ISO 14649 data model for turn/mill machining.
\end{abstract}

Keywords: STEP, STEP-NC, ISO 10303, ISO 14649, mill/turn machining, CAM

\section{INTRODUCTION}

The need for an efficient method for data exchange has been a requirement since the first applications of CAD/ CAM (computer-aided design/manufacture) systems. Over the last three decades, there has been a number of efforts to create a suitable standard for data exchange, namely the AECMA (European Association of Aerospace Industries) format, the German VDA (Verbandes der Deutchen Automobilendustrie) standard, the French SET (Standard d'Echange et de Transfert) and the IGES (Initial Graphics Exchange Specifications) and PDES (Product Data Exchange Specification) formats from the United States [1]. Later PDES was proposed to ISO TC $184 / \mathrm{SC} 4$ (Technical Committee 184 /Subcommittee 4) and was considered as the basis to what is known today as the ISO 10303 [2] standard, commonly termed STEP [1]. It should be recognized that the STEP standard was conceived to represent the whole life cycle of a product. However, the authors believe that to date the development of STEP has been primarily focused at product design information, with little emphasis on manufacture, and in particular CNC (computer numerical control) machining.

Over the last 10 years, significant efforts have been directed in the development of a new ISO standard based on STEP to bridge the information divide between

\footnotetext{
The MS was received on 9 February 2004 and was accepted after revision for publication on 21 July 204.

*Corresponding author: Wolfson School of Mechanical and Manufacturing Engineering, Loughborough University, Loughborough, LeicestershireLE11 3TU, UK. E-mail: S.T.Newman@lboro.ac.uk
}

product design and $\mathrm{CNC}$ manufacture. To solve these problems a new data interface entitled ISO $14649[\mathbf{3}, \mathbf{4}]$ (known as STEP-NC) has been developed under the ISO Technical Committee TC184 in the Subcommittee SC1 Workgroup WG7 based on ISO 10303. The introduction of this standard aims to integrate STEPcompliant information across the whole product cycle of CAD, CAPP, CAM and CNC (computer aided design/process planning/manufacture/numerical control). Although the use of STEP-NC has been tested independently for milling and turning operations $[\mathbf{5}, \mathbf{6}]$, at present only a few applications of the combined turn/mill operations for asymmetric rotational parts have been reported in the literature [7-9].

The authors define an asymmetric rotational part as a component that has a number of turning processes with additional milling processes as complementary processes (as shown in Fig. 1). These types of parts are now commonly produced economically on turn/mill centres.

This paper presents ongoing research focused on the design of a STEP-NC compliant CAM system for asymmetric rotational parts, based on both turning and milling operations. The current ISO 14649 data models are explicitly not defined for combined milling and turning. This paper identifies a view of how ISO 14649 can be used to combine turning and milling operations to achieve the complete machining of rotational asymmetric components at a single turning centre. The use of the individual parts of the evolving standard ISO 14649, namely Parts 10, 11, 12, 111 and 121 [11-15] has been investigated to provide the means to represent STEP-compliant turn/mill component programs. 


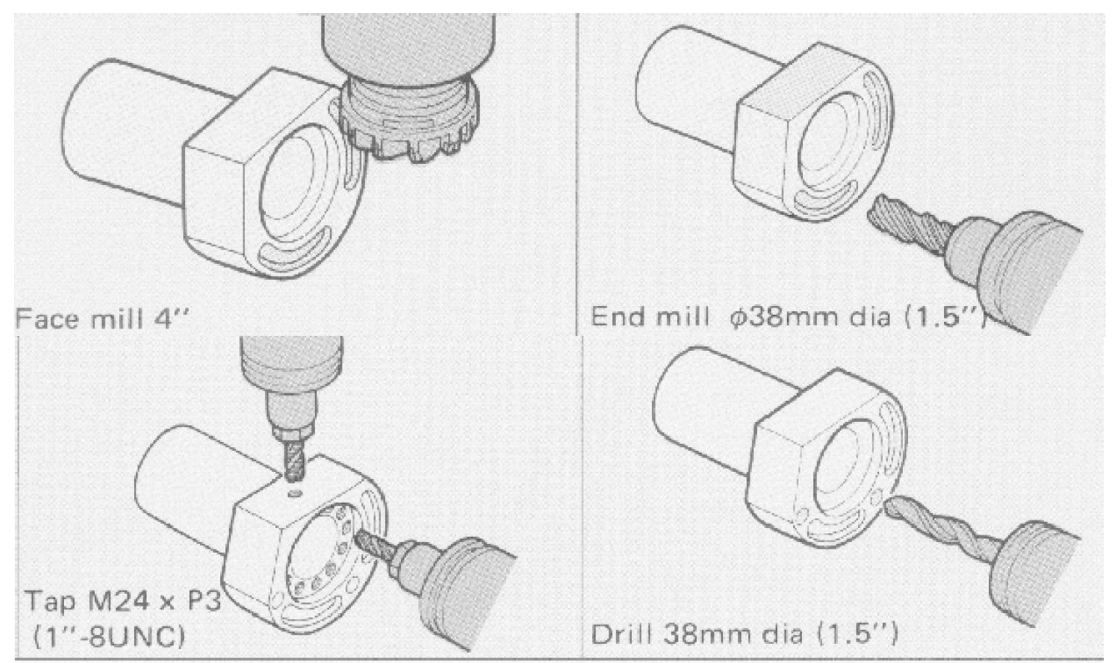

Fig. 1 Facing, grooving and out of centre drilling operations over an asymmetric rotational part [10]

\section{TURN/MILL CENTRES AND ASYMMETRIC ROTATIONAL PARTS}

The literature reports that 47 per cent of machined components are rotational and from these 75 per cent have additional milling features [16]. This highlights a need to machine asymmetric rotational parts efficiently, which has resulted in the development of turning centres with milling and turning capabilities. Figure 2 illustrates an example of a dual spindle and dual turret turn/mill centre configuration with nine axes of movement, which highlight the significant complexity involved in programming of asymmetric rotational parts within turn/mill centres. These turning centres with multiaxes, multispindles and multiturrets using milling and turning tools are now becoming commonplace in industry. As a consequence, there is a requirement for programming of complete components at a single machine with turning and milling operations, which has led the software industry to develop a number of CAM and verification systems to aid this complex type of part programming. However, the introduction of STEP-NC highlights a need for new programming methods and software tools for turn/mill machining of components, which requires further research to support industrial developments.

\section{THE STEP-NC (ISO 14649 STANDARD) AND ITS BENEFITS}

For decades NC programming has been based on the tool path description and machine functions that were performed by the $\mathrm{G} / \mathrm{M}$ codes provided in the ISO 6983 standard [17]. In contrast, the ISO 14649 is not a

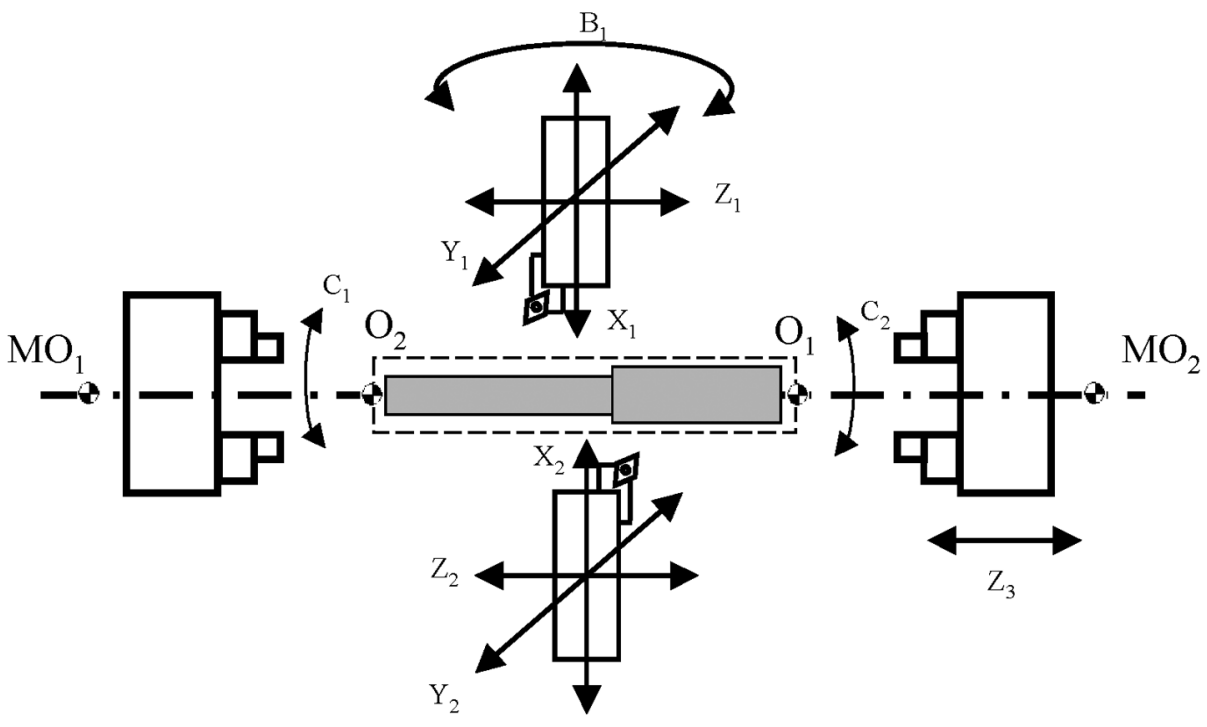

Fig. 2 Dual spindle and dual turret on a nine-axis turn/mill centre 


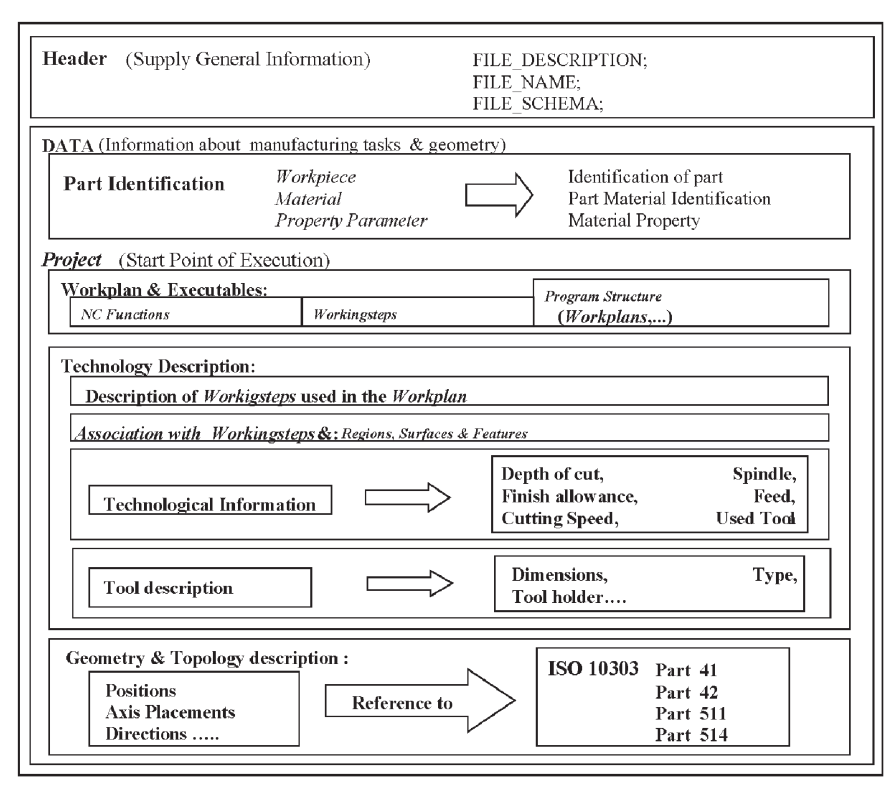

a - The Structure of STEP-NC program

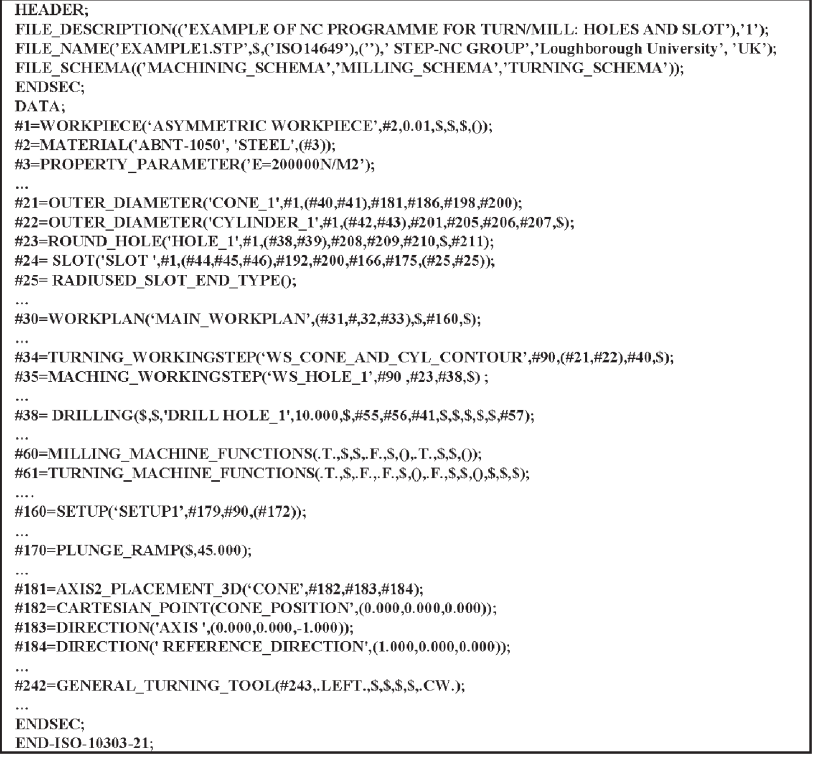

b - Authors vision of a STEP-NC physical file for turn/mill component

Fig. 3 The STEP-NC program

method for programming and, although the tool movements for a CNC machine exist as an option, the standard offers better capabilities using manufacturing features. ISO 14649 provides an object-oriented data model for CNCs with a detailed and structured data interface [4]. The ISO 14649 standard contains a range of information, such as the features to be machined, the operations to be performed, tool types to be used (the technology), workingsteps (description of program tasks), workplan (sequence of the workingsteps), clamping and part set-up data. It could be said that a STEP$\mathrm{NC}$ physical file is a mix of an NC program and process plan because it carries information about geometry, tooling, strategies, operations and operation sequencing.

For each operation performed on one or more features, a statement termed a workingstep is defined. These workingsteps provide the basis of the workplan to manufacture the component. Figure $3 \mathrm{a}$ shows the general structure of the ISO 14649 data for its physical file and Fig. 3b depicts a vision of the authors' view of a STEP-NC program to represent a turn/mill component. This vision combines the ISO 14649 Parts 10, 11 and 12 together with their respective ISO 14649 tooling Parts 111 and 121 .

One of the expected benefits from STEP-NC is the ability to represent component geometry in the controller, either through features or by complex regions. However, STEP-NC goes further and has a more comprehensive data model that overcomes the lack of process information in ISO 6983 files $(\mathrm{G} / \mathrm{M}$ code programming) [17]. The STEP-compliant approach brings the possibility of integrating the machine controller to the overall enterprise information network, with the intention to have bidirectional data flow. This will provide the novel capability for upstream feedback of information from the numerical controller to the design and process areas in the company $[\mathbf{4}, \mathbf{1 8}-\mathbf{2 0}]$. Figure 4 depicts the differences between the current state of art in $\mathrm{NC}$ manufacture where data flow is unidirectional from the $\mathrm{CAD} / \mathrm{CAM}$ system to the $\mathrm{CNC}$ and bidirectional when using STEP-NC. Although this approach has been partially adopted commercially by some CAM/CNC systems, such as the CAMWARE/Mazatrol system [21], these systems use their own proprietary data format which does not allow integration into a company's product and manufacturing data models. In addition, when using ISO 6983 the information available in the $\mathrm{CAD} / \mathrm{CAM}$ system is partially lost when postprocessed into $\mathrm{G} / \mathrm{M}$ codes, as the standard does not provide support for most of the information $[4,18]$.

In comparison, the ISO 14649 standard provides a feature-based object-oriented data model for the next generation of intelligent CNCs [3]. It is systematically detailed with a structured data interface that incorporates the component geometry through feature-based programming.

Part program portability has been a problem for $\mathrm{CNC}$ manufacture for many years. This can be achieved through STEP-NC, which is a generic data model, which aims to manufacture parts on different $\mathrm{CNC}$ machines. The difference in the use of STEP-NC from the current ISO 6983 standard rests in the very essence of STEP. The information is written using a well-defined formal language titled EXPRESS [22], and is defined by 


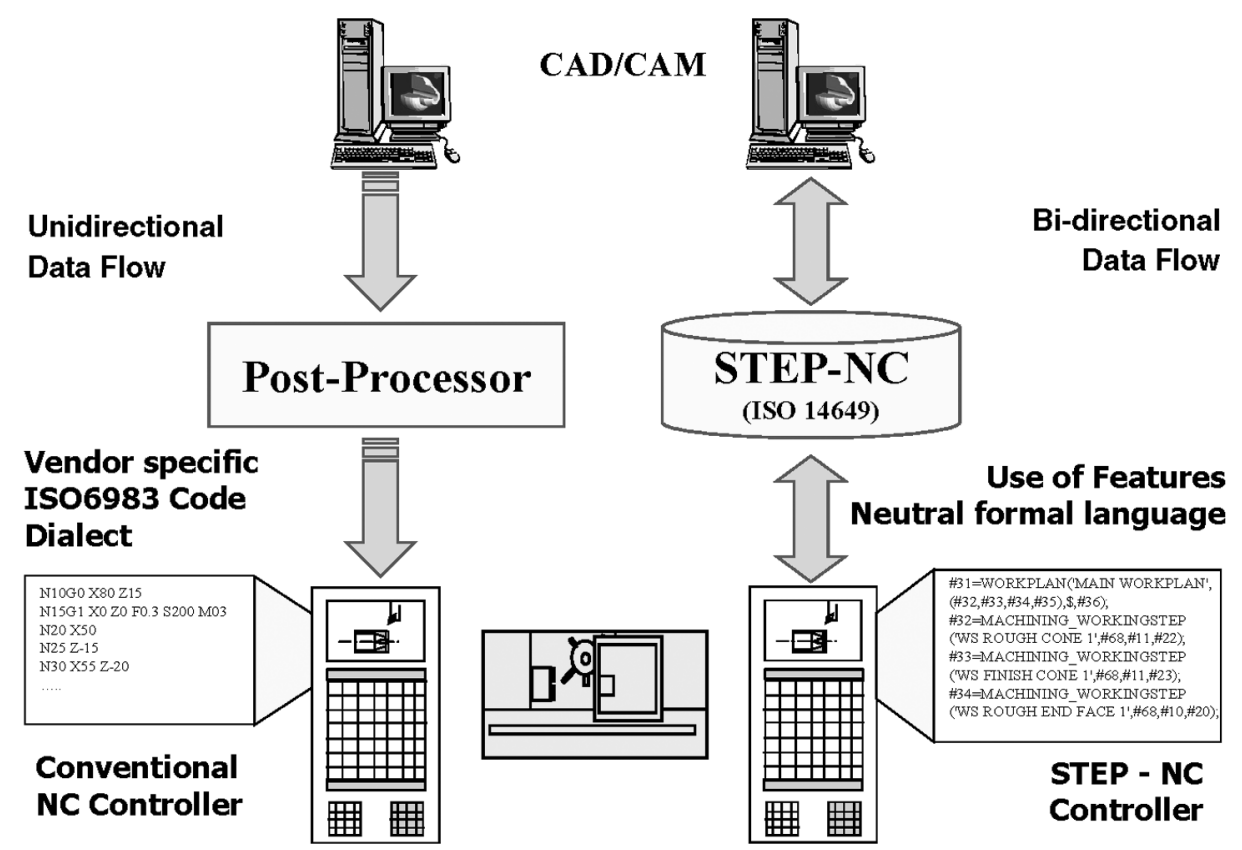

Fig. 4 Comparison between the current NC interface and the new data interface based on STEP-NC

one or more of the STEP schemas, such as milling and turning. Therefore, in a well-defined semantic domain, there are also conformance tests provided by STEP to ensure the compliance with the standards. Contrary to ISO 6983, STEP-NC only allows the use of standard syntax and semantics as outlined in the ISO 14649 standards. This avoids the problem existing today, where for each particular improvement in a given controller the builder writes an extension for a new subset of instructions in $\mathrm{G} / \mathrm{M}$ codes.

It is worth noting that currently two versions of STEP$\mathrm{NC}$ are being developed by ISO. The first is the Application Reference Model (ARM) version of ISO 14649 and the other is the ISO 10303 AP238 [23], the Application Interpreted Model (AIM) version of ISO 14649 [3]. This work uses the ARM version as the current version of AP238 has no support for turning as yet and in fact the ARM is simpler than the AIM to implement. For more information about the use and differences between the two versions readers are referred to references [24] and [25].

\section{APPLICATION OF STEP-NC FOR PROGRAMMING ASYMMETRIC ROTATIONAL PARTS}

There are a number of issues involved in the design and implementation of a STEP-compliant CAM system. They range from problems such as the suitability of features and the application of machining strategies to the capture of the embedded knowledge of the CNC by the CAM system and the $\mathrm{NC}$ tool path simulation.
However, the application of this new standard for rotational asymmetric parts brings additional considerations as the combination of turn and milling operations is not trivial. In this paper the area of feature representation for use of milling and drilling operations using the current parts of the standard is discussed.

\subsection{STEP-NC feature representation}

The ISO 14649 standard uses features in a close resemblance to the well-established ISO 10303-224 (AP224) [26] standard. This has the advantage of contributing to a better understanding of STEP-NC for manufacturing engineers as STEP-NC features have a terminology and structure that greater resemble common industrial practice. It also brings forth the additional disadvantage of mapping AP224 features to those in STEP$\mathrm{NC}$ features, which is an overhead from the information model integration viewpoint. Therefore, significant effort has been directed at making the STEP-NC features consistent with the AP224 standard.

The STEP-NC definition for turning features, as defined in ISO 14649 Part 12, assumes that features only lie symmetrically around the workpiece's $Z$ axis. Currently the individual STEP-NC standards related to milling and turning do not address the issues of turn/ mill features and their operations. Features machined usually using the $Y, C$ and $B$ axes, such as a helix, cam and planar surface (other than the end face of the workpiece), are not yet defined in this schema. However, in this work the authors claim that some of the milling and drilling can and has been used in the turn/mill envir- 
onment. As an example, milling features such as a pocket, hole and slot can be used in particular situations, as discussed below.

To create the milling features at the end face of a rotational workpiece, the process is represented within the STEP-NC standard without a problem as the $Z$ axis is perpendicular to this surface, as required for milling in ISO 14649. The problem would occur when the milling feature is placed on a surface of revolution of a turned part, as when using the $C$ or $B$ axis in an ISO $6983 \mathrm{com}$ pliant controller. The STEP-NC definition of $2 \frac{1}{2}$-dimensional milling and drilling features and their respective operations is based on the assumption of a prismatic part with a planar surface, from where the depth is measured and the machining of a feature is in the local $Z$ direction of the feature. Therefore, at a first view the positioning over a revolved surface would bring the need to redefine some of the features from ISO 14649 Part 10 (general data). However, the authors show that the existing STEP-NC features, such as a hole, pocket and slot, can be used effectively in both the face and the revolution surface of a turning part by translation and rotation of their own coordinate system. Translation and rotation functions over the features' coordinate system are already provided in ISO 14649 Part 10. In fact, one of the issues would be how to define the semantics of the depth in such a situation, but this is also supported by the STEP-NC standard. The ISO 14649 Part 10 states that 'The depth of the feature is described by a plane which includes the lowest points of the feature $(z<0)$ measured in the feature's local Cartesian-coordinate system' [11]. Figure 5 depicts the case of a slot on a surface of revolution, where $X, Y$ and $Z$ are the axes of the workpiece coordinate system and the $X^{\prime}, Y^{\prime}$ and $Z^{\prime}$ are the axes of the feature's coordinate system. Thus, there is an implicit plane, tangent to the revolved surface, at the point of the feature placement. Therefore, the feature can be placed on the revolved surface of the component. These arguments can be easily extended to features such as pockets, holes and steps, which are commonly found on the turn/mill components.

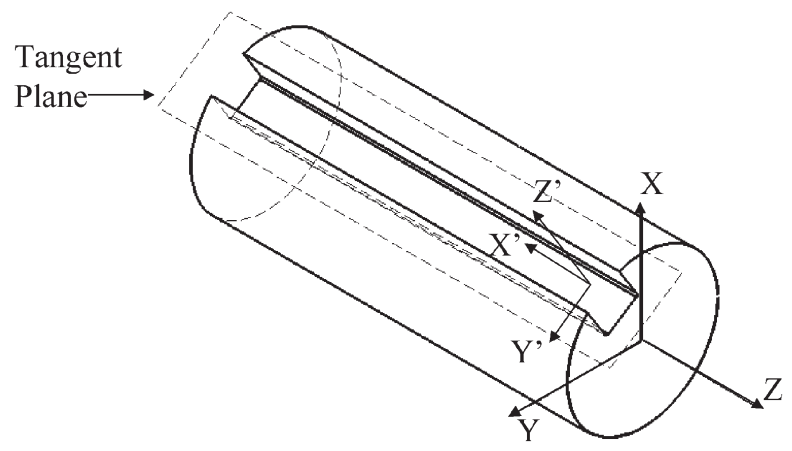

Fig. 5 Translation and rotation of the feature's coordinate system

\section{DISCUSSION AND CONCLUSION}

The recent development in ISO 14649, termed STEP$\mathrm{NC}$, provides an exciting solution for $\mathrm{CAD} / \mathrm{CAM}$ and $\mathrm{CNC}$ integration, with reported successful application in turning and milling operations. However, at the present time, there is no publication of an ISO 14649 standard for turn/mill machining. This paper proposes to combine the data models used in Parts 10, 11, 12, 111 and 121 of ISO 14649 for the design of CAM systems, which are based on an amalgamated data model supported by ISO 14649. Although they do not have all necessary features, these Parts of ISO 14649 provide the means to represent a limited set of features and operations in a turn/mill environment.

The main issue that has been addressed by this paper is the problem of feature positioning and operation, which can be easily overcome through the use of ISO 14649 Part 10, as discussed in section 4 .

The use of STEP-NC for CAM/CNC brings the benefit of better integration in the information model from design to manufacture and avoiding semantic errors, giving an end to the translation between proprietary and non-proprietary formats. However, there is still the need for further research and development of a STEP standard, which will provide the means for a fully feature based turn/mill programming capability using STEP-NC to match the increasing flexibility of $\mathrm{CNC}$ turn/mill machine tools.

\section{ACKNOWLEDGEMENTS}

The authors wish to thank Loughborough University, the State University of Santa Catarina (UDESC, Brazil) and Conselho Nacional de Ciencia e Tecnologia (CNPq, Brazil) in support of the studentships to undertake this research.

\section{REFERENCES}

1 Kemmerer, S. J. (Ed.) STEP. The Grand Experience, July 1999 (Manufacturing Engineering Laboratory, National Institute of Standards and Technology, Gaithersburg, Maryland).

2 ISO 10303-1 Industrial Automation Systems and Integration-Product Data Representation and Exchange. Part 1. Overview and Fundamental Principles, 1994 (International Organization for Standardization, Geneva, Switzerland).

3 ISO/FDIS 14649-1 Industrial Automation Systems and Integration-Physical Device Control-Data Model for Computerized Numerical Controllers-Part 1: Overview and Fundamental Principles, November 2002 (International Organization for Standardization, Geneva, Switzerland).

4 Weck, M, Wolf, J. and Kiritis, D. STEP-NC-the STEP compliant NC programming interface: evaluation and improvement of the modern interface. In IMS Forum, Ascona, Switzerland, October 2001. 
5 STEP-NC Project, ESPRIT Project EP 29708; STEP-Compliant Data Interface for Numerical Controls (STEP-NC) In STEP-NC Newsletter, Issue 3, November 2000; also available in the URL: http://www.step-nc.org on 11 November 2003.

6 STEP-NC Project, EC, GROWTH Project IMS STEP-NC (STEP-NC). In STEP-NC Newsletter, Issue 5, September 2003; also available in the URL: http://www.step-nc.org on 11 November 2003.

7 Klemm, P. and Heusinger, S. Einheitliche Datenbasis in der Prozesskette-STEP-NC basiertes NC Planung in der Komplettbearbeitung steigert die Effizienz im Produktionsablauf. Maschinenmarkt-Das Industriemagazin, 2003, 39, 24-27.

8 Klemm, P. and Heusinger, S. Planungsfehler werden Vermieden-STEP-NC Basiertes Programmieren der Komplettbearbeitung auf Dreh-Fraszentren verkurst Programmiertzeiten. Maschinenmarkt-Das Industriemagazin, 2003, 45, 26-29

9 Rosso Jr., R. S. U. and Newman, S. T. Estrutura de Dados para Sistemas CAD/CAM aderente à STEP. In VI Congresso Ibero-Americano de Engenharia Mecânica, Universidade de Coimbra, Coimbra, Portugal, 15-18 October 2003, Vol. 2, pp. 1019-1024.

10 Yamazaki Mazak Corp. Slant Turn 40N ATC Mill Center, Publicity Material, Yamazaki Machinery UK Limited, 1994.

11 ISO/FDIS 14649-10 Industrial Automation Systems and Integration-Physical Device Control-Data Model for Computerized Numerical Controllers-Part 10: General Process Data, November 2002 (International Organization for Standardization, Geneva, Switzerland).

12 ISO/FDIS 14649-11 Industrial Automation Systems and Integration-Physical Device Control-Data Model for Computerized Numerical Controllers-Part 11: Process Data for Milling, November 2002 (International Organization for Standardization, Geneva, Switzerland).

13 ISO/DIS 14649-12 Industrial Automation Systems and Integration - Physical Device Control - Data Model for Computerized Numerical Controllers-Part 12: Process Data for Turning, 28 February 2003 (International Organization for Standardization, Geneva, Switzerland).

14 ISO/FDIS 14649-111 Industrial Automation Systems and Integration-Physical Device Control-Data Model for Computerized Numerical Controllers-Part 111: Tools for Milling, 28 September 2000 (International Organization for Standardization, Geneva, Switzerland).

15 ISO/DIS 14649-121 Industrial Automation Systems and Integration-Physical Device Control-Data Model for Computerized Numerical Controllers-Part 121: Tools for Turning, 28 February 2003 (International Organization for Standardization, Geneva, Switzerland).

16 Tavakoli Bina, A. Feature based workshop oriented NC planning for asymmetric rotational parts. $\mathrm{PhD}$ thesis,
Department of Manufacturing Engineering. Loughborough University, March 1993.

17 ISO 6983/1 Numerical Control of Machines-Program Format and Definition of Address Words-Part 1: Data Format for Positioning, Line and Contouring Control Systems, 1st edition, 15 September 1982 (International Organization for Standardization, Geneva, Switzerland).

18 Proctor, F. M., Michaloski, J. L. and Shackleford, W. P. Tying together design, process planning and machining with STEP-NC technology. In the Fifth Biannual World Automation Congress, Orlando, Florida, February 2002; also in Robotics, Manufacturing, Automation and Control, 2002, Vol. 14, pp. 33-38 (TSI Press, Albuquerque, New Mexico).

19 Rosso Jr., R. S. U., Allen, R. D. and Newman, S. T. Future issues for $\mathrm{CAD} / \mathrm{CAM}$ and intelligent manufacture. In Proceedings of the 19th International Manufacturing Conference (IMC-19), Queen's University Belfast, Belfast, Northern Ireland, 28-30 August 2002, pp, 115-124.

20 Newman, S. T., Allen, R. D. and Rosso Jr, R. S. U. $\mathrm{CAD} / \mathrm{CAM}$ solutions for STEP compliant CNC manufacture. Int. J. Computer Integrated $M f g, 2003$, 16(7-8), 590-597.

21 Mazatrol Fusion 640, Publicity Material, Yamazaki Mazak Company Limited; also available in the URL: http:// www.mazakusa.com/ on 1 December 2003.

22 ISO 10303-11 Industrial Automation Systems and Integration-Product Data Representation and Exchange-Part 11: Description Methods: The EXPRESS Language Reference Manual, 1st edition, 15 December 1994, Corrigendum 1, 1999 (International Organization for Standardization, Geneva, Switzerland).

23 ISO/CD 10303-238 Industrial Automation Systems and Integration - Product Data Representation and Exchange-Part 238: Application Protocol: Application Interpreted Model for Computerized Numerical Controllers, 3 June 2002 (International Organization for Standardization, Geneva, Switzerland).

24 Wolf, J. Requirements in NC machining and use cases for STEP-NC-Analysis of ISO 14649 (ARM) and AP 238 (AIM). In ISO T24 STEP-Manufacturing Meeting, San Diego, California, 7 March 2003, White Paper.

25 Feeney, A. B., Kramer, T., Proctor, F., Hardwick M. and Loffredo, D. STEP-NC implementation-ARM or AIM? In ISO T24 STEP-Manufacturing Meeting, San Diego, California, 7 March 2003, White Paper.

26 ISO 10303 Industrial Automation Systems and IntegrationProduct Data Representation and Exchange-Part 224: Application Protocol: Mechanical Product Definition for Process Planning Using Machining Features, December 2000 (International Organization for Standardization, Geneva, Switzerland). 